\title{
A Life Well-Lived: Discovering Motivation and Deeper Relationships by Contemplating Our Own Mortality
}

Austin Williams 


\section{Abstract}

For centuries, religious authorities and social pressures have discouraged individualsfrom contemplating mortality. A key component to the human sense of self is the ability to acknowledge the finite nature of life. All people experience some sort of death anxiety, whether conscious or not. Some experience thanatophobia, the fear of dying, more strongly than others. If managed in a healthy manner, death anxiety can serve as a motivating force to live a fuller life and deepen relationships with family and friends. In recognizing hidden components of death anxiety and finding consolation for the inevitability of dying, we can acknowledge our own mortality and explore both secular and spiritual approaches to death. For this thesis, I use painting as a visual medium to deliver my ideas and research in an immersive experience to the viewer. I conducted research by reading books and poetry, taking photographs, and viewing other artists' work, online and in-person, from New York City museums and galleries. I have produced ten paintings of various size and technique that communicate how science and medicine, faith, meditation, and relationships alleviate death anxiety. Ultimately, I have found that painting has helped me to develop coping mechanisms that lessen my own death anxiety. I hope that by viewing my art, people will feel encouraged to consider aspects of their own mortality as well as ways to lead a fulfilling life.

The ability to distinguish between living and dead organisms marks a developmental milestone in animal awareness. Human intellect evolved to recognize that, like other species, all people will eventually die. The ability to recognize one's own mortality is critical to the human sense of finite self. Thanatophobia, or the fear of dying, is universally experienced - directly or subconsciously - by all people. This shared fear may be why most of the world's diverse theologies promise some sort of afterlife. Existential thoughts, however, are deeply personal, and so coping mechanisms are unique to each individual. Through this project, I explore such themes as the conceptual grounds for a series of original oil paintings. In this document, I articulate my research and my beliefs as they relate to my paintings. Beginning with Remembrance, the starting point of my thesis, I discuss each painting in chronological order. Additionally, I address the concepts and techniques behind the work as well as the implications on reducing death anxiety.

Members of cultural communities and religious congregations share common core beliefs, but death anxiety cannot be collectively experienced. Instead, it exists within individuals due to a complex stratification of experiences, beliefs, and social influences. Individuals construct their own detailed beliefs and practices to alleviate internal soreness surrounding death. Religious leaders have generated institutionalized power over societies through centuries of threatening eternal damnation with gory visualizations, which antagonizes thanatophobia and discourages dialogue about mortality. ${ }^{1}$ By approaching death anxiety directly through contemplation and in- depth focus, as performed in my artistic process, it is possible to unveil our own fears and adopt coping mechanisms. Individualized methods depend on the open-minded appraisal of new practices and connection to community. Therefore, to recognize hidden components of death anxiety and find consolation for the inevitability

${ }^{1}$ Yalom, Irving D. Staring at the Sun: Overcoming the Terror of Death. San Francisco: Jossey-Bass, 2008, 81. 
of dying, of death anxiety and find consolation for the inevitability of dying, we must acknowledge our own mortality and explore both secular and religious approaches to death.

My interest in mortality strengthened following a personal "Awakening Experience," - the moment I realized that I am not immortal. ${ }^{2}$ Two decades of my life passed by before I fully understood that my biological life is finite, which is a prominent realization for young adults as their brains finish developing. During the spring 2019 semester in Advanced Painting, my class traveled to the University of North Texas Health Science Center, where we had the opportunity to create graphite and watercolor sketches of a cadaver and preserved organs. Outside of funerals I attended as a child, I had never seen a human corpse before, let alone one dissected. Later, I would witness deaths in the emergency room as a student observer. I was both caught unaware and fearfully fascinated. The lab instructor mentioned special memorial days during which students and faculty observe a moment of silence to honor and celebrate the donors who left their bodies for students' medical education.

This off campus site visit was part of an open-ended painting assignment titled "The Body." I painted Remembrance (2019), in which a man lays amongst peony flowers and silver-dollar eucalyptus leaves, his chest surgically opened to reveal his heart and lungs. I wanted the piece to convey the sense of awe and respect that I felt in the cadaver lab, so I painted realistically, using online three-dimensional anatomical models to capture the crude details and subtle beauty of body donation. The painting is twenty-four by thirty inches, which presents the figure as slightly larger than life to highlight the human body. Spending time amongst the dead or painting organs for hours on end brought my attention to how I would leave my

Remembrance (2019) 24 x 30 inches Oil on canvas over panel

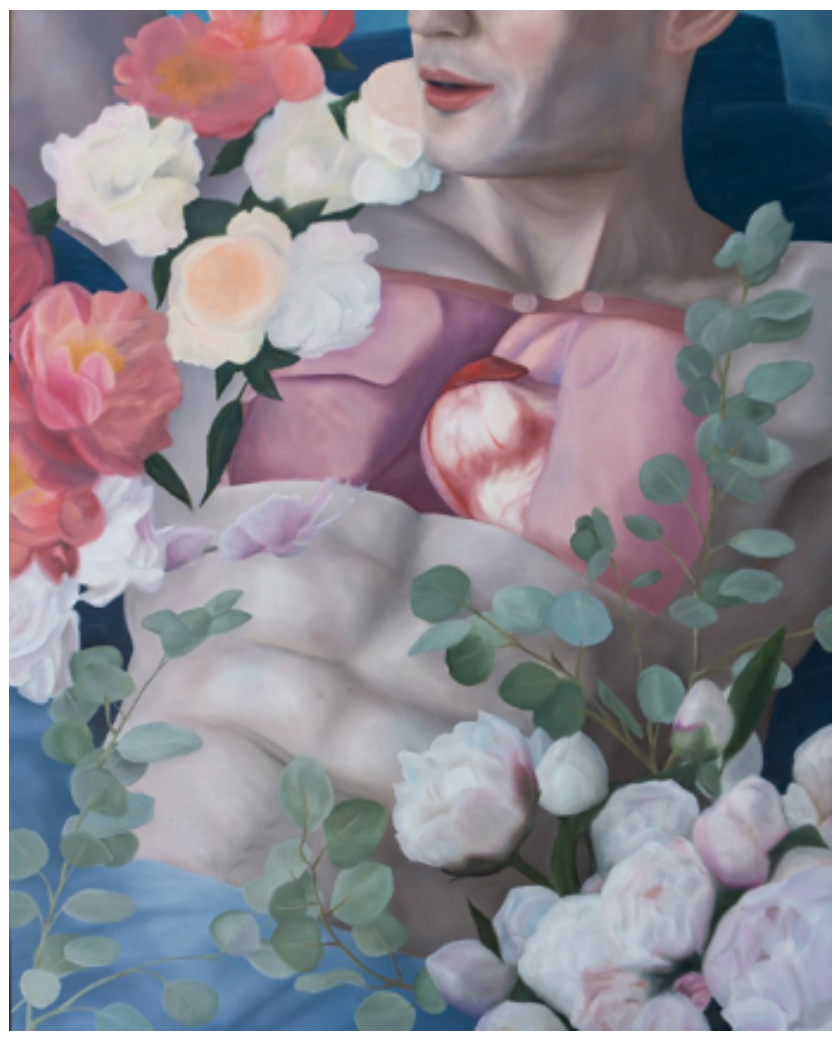


own body after my death. I experienced then what existential psychiatrist Dr. Irving Yalom would refer to as an "Awakening Experience." For some time, I was hyper-focused on my own mortality. My sense of dread and longing for peace is the driving force for my thesis. By actively contemplating death, I have managed to develop coping mechanisms. Additionally, I've gained a greater motivation to seek out more fulfilling experiences and develop deeper personal relationships with family and friends. To explore these concepts more fully, and based on the results of my painting Remembrance, I chose to present my senior honors thesis through a series of paintings. I want viewers to come away from these paintings feeling encouraged to explore the same concepts surrounding death that I was experiencing.

To accomplish this project's thematic goals, I deepened my understanding of physical substrate construction. The material presence of a painting serves as the foundation of how viewers experience ideas. As encouraged by Professor Adam Fung, I constructed many of my own substrates to customize their textures and structure. Because I delivered rather thin layers, I prefered painting on canvas; the texture of which I found held onto paint during blending better than smoother panels. I primed my surfaces with enough thin layers of gesso to protect the fibers and leveled the pores to smooth the surface while allowing the weave to stand through. I disliked the movement of stretched canvas when painted on vigorously, which I often do to blend colors. Therefore, I stretched all of my canvas over wood or Masonite panels, which gave the stretcher more structure and secured the canvas in place. For this reason, I also began purchasing premade wooden panels and stretching canvas over them to save time while still customizing my surfaces.

In addition to physical construction, I also developed stronger methods of collecting source images and constructing my composition. To conceptualize the painting, I often sketched a few thumbnails before settling on an idea. I began to collect reference images either from my own photography documentation or online sources. For figurative references, I took photographs of myself and friends for paintings using a Sony a6000 or my iPhone. I arranged images in Adobe Photoshop, manipulating the composition and palette, before settling on a digital rendering. By projection or by using Conté on the back of a printed image, I then transfered the digital rendering onto a canvas. I mixed a series of paint colors and catalogued them into a coherent palette that I used to develop the same colors again for the piece. In my paintings, I usually paint wet-into-wet (allaprima) and develop a satisfying first layer, returning to add detail in sequential layers. For example, the background of Tombstone Among the Grass (2020) contains four layers occasionally sanded, followed by the tombstone itself which I produced over an additional four layers to develop the desired dry texture of limestone. At the time of writing this, many of these paintings will not have dried long enough to seal with a final varnish, since oil paint cracks if not cured with adequate exposure to air. To level areas of uneven sheen, I finalized pieces with retouch varnish, which is thin enough to allow complete drying and accommodates additional layers of paint as needed.

Though the generation of detail is often a laborious task, I paint highly accurate renderings to clearly communicate my ideas to the viewer. Painting has an immersive quality for both the artist and the viewer, helping the latter to consider their own mortality. Thanatophobia is, by its very nature, a deeply personal matter. Through my paintings, I hope to convey that as a human being, I also feel death anxiety. While death is amongst the most universal features of the human experience, the mechanisms individuals use to cope with mortality are individually unique. Many develop an unshakable confidence 
Tombstone Amongst the Grass (2020) 9 x 12 inches Oil on Canvas over Panel

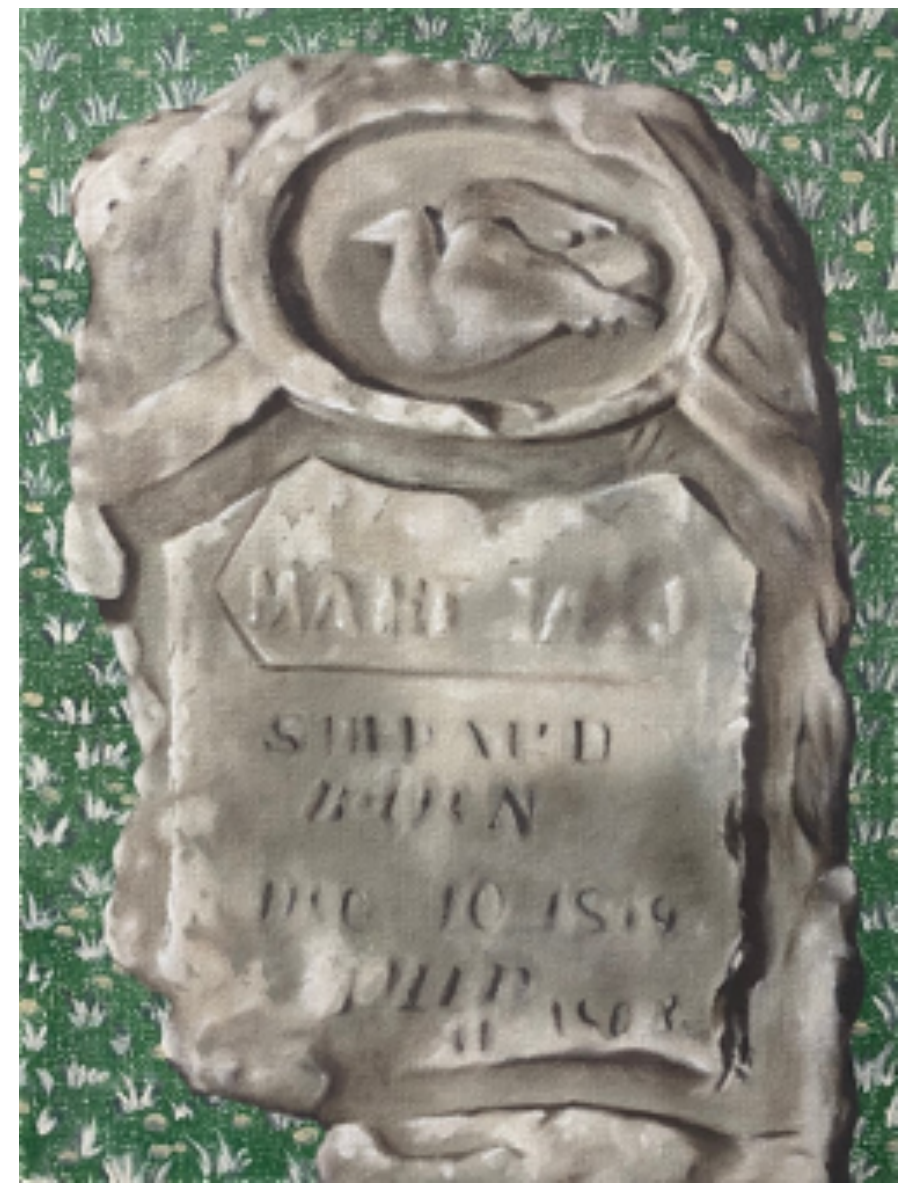

in their beliefs. Perceptions of absolute truths and divine encounters continue to sculpt human history. However elaborate our imaginations may be, nobody can definitively foresee what happens after death, for logic cannot faithfully predict a terrain the brain cannot survey. In the first painting for my thesis project, a self-portrait, Self (2019), I imagined how I could exist after dying. Theistically, perhaps my soul persists in some eternal, conscious form. The golden transparency of the second figure emerges from a Protestant Christian upbringing, illustrating the distinction between the non-material eternal spirit from the material body. Atheistically, I position a pale shadow behind the second figure, implying that the mind and body are inseparable and transient. In this manner, after death, we only exist in the memories of others; even here, our shadow is temporary. Self (2019) forced me to consider my own mortality and imagine the retention of consciousness, or the complete lack thereof into the afterlife.

In the background, a snake climbs and a dove stretches amongst the foliage, symbolizing Hermes' staff, the Caduceus. Many medical organizations arbitrarily use the Caduceus as their symbol, mistaking it for the Rod of Asclepius. ${ }^{3}$ Continuous with contemporary iconography, I symbolize medicine with the Caduceus. Later, I will discuss the Greek mythology of Asclepius, as it directly relates to healing and immortality.

\footnotetext{
3 “The Rod of Asclepius and Caduceus: Two Ancient Symbols." Florence Inferno. Last modified June 22, 2016. https:// www.florenceinferno.com/rod-of-asclepius-and-caduceus-symbols/.
} 


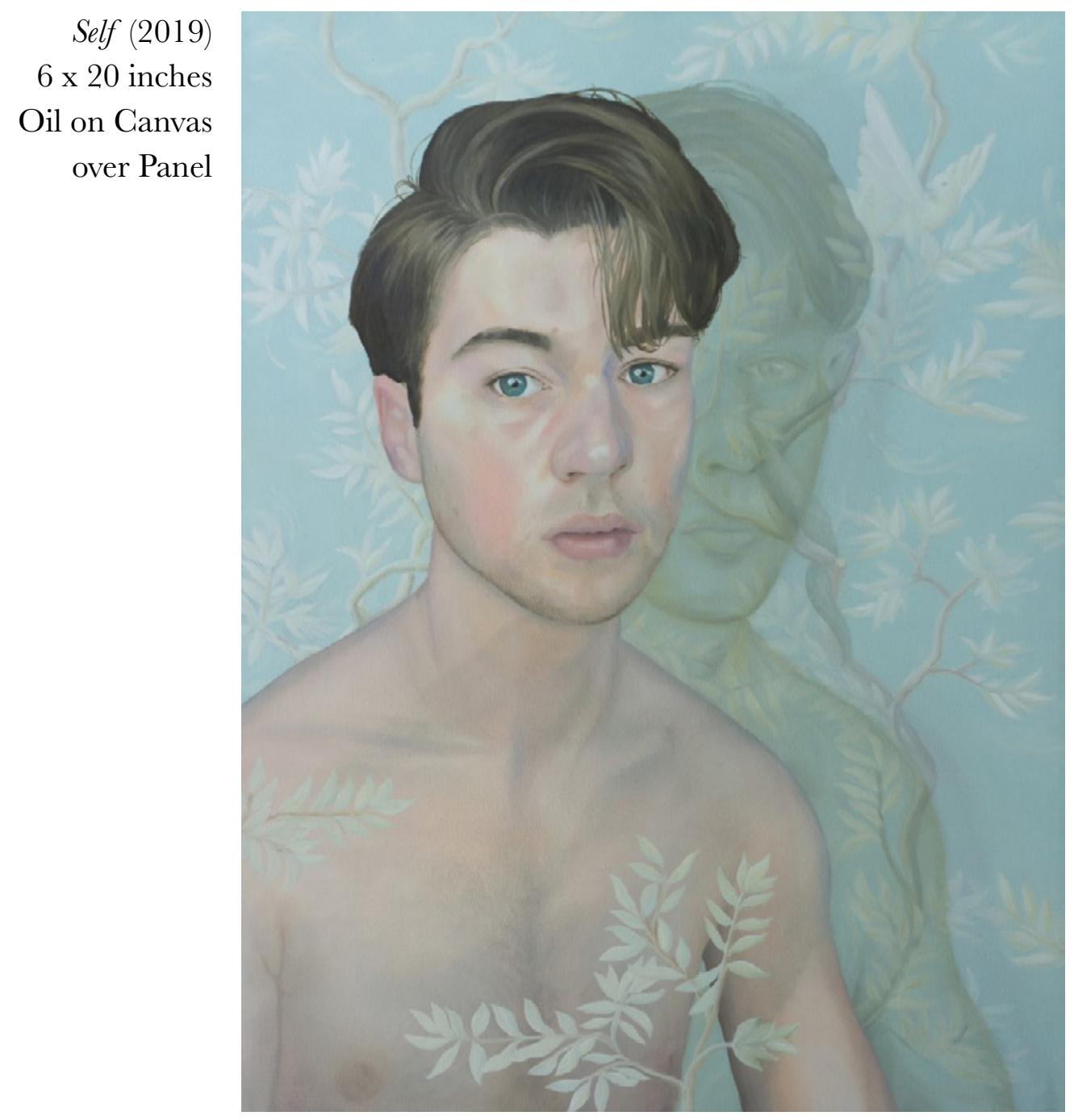

Science contributes to the span and quality of human life by seeking to explain the mechanisms behind health and illness. Medicine bridges the applications of science and faith when culturally competent healthcare professionals strive to curate treatment plans that respect their patients' beliefs. However, contemporary science cannot yet overcome the reality that all beings are mortal. As powerful as medicine can be, research increasingly reveals an unanticipated complexity of the biological system, including natural limits to longevity. Humans are eukaryotic organisms, a domain of life which encodes genetic information on linear DNA chromosomes. Cells naturally die over time but replenish themselves via mitosis, during which the cell duplicates the genome and divides into two daughter cells. During each round of division, the chromosomes shorten as a consequence of how linear DNA replicates. Normally, this is not an issue because the fractions lost contain only repeated sequences called telomeres, which do not encode for proteins. However, as we age, many repeated rounds of cellular division shorten the telomeres to the point that they cannot protect vital genetic information deeper within the chromosomes. At this point, cells stop dividing, and the body cannot repair itself following damage or infection. Eventually, the effects of aging become apparent. 
Many hope that our species overcomes mortality by scientific means. Researchers have found that the naked mole rat has evolved special enzymes to evade aging. ${ }^{4}$ By turning on telomerase activity throughout life, their chromosomes do not shorten, essentially pausing the effects of time on their bodies. The enzyme telomerase is active in the developing human embryo. Perhaps by reactivating the enzyme in adult human cells, scientists could reverse the effects of aging, achieving immortality and resolving death anxiety. However, in human cells, stimulating telomerase activity is a critical step for cancer cells to divide enough to develop tumors. It seems that if scientists activated this gene in our bodies, we would develop cancer, and without a cure, die from the disease. As much as science can conceptualize immortality, there are natural limits to the longevity of the organic form. Our motivation to live forever stems from thanatophobia. Perhaps someday, immortality will serve as a cure to the fear of dying of old age, but it does not protect us from intended violence or accidents. Furthermore, evidence from patients suffering from dementia and cancer suggests that humans already live too long, adding yet another complexity to immortality. Nevertheless, contemporary science consoles many to believe that advanced medicine might spare them from dying.

I explored the notion that through immortality, we may overtake thanatophobia in Our Chains Encode Us (2019), which superimposes the Caduceus onto the myth of Icarus to illustrate the rise of modern medicine. Although I respected common iconography by using the Caduceus to represent medicine, here I will discuss the Greek myth of the demigod Asclepius. His father Apollo grants him gifts of healing and

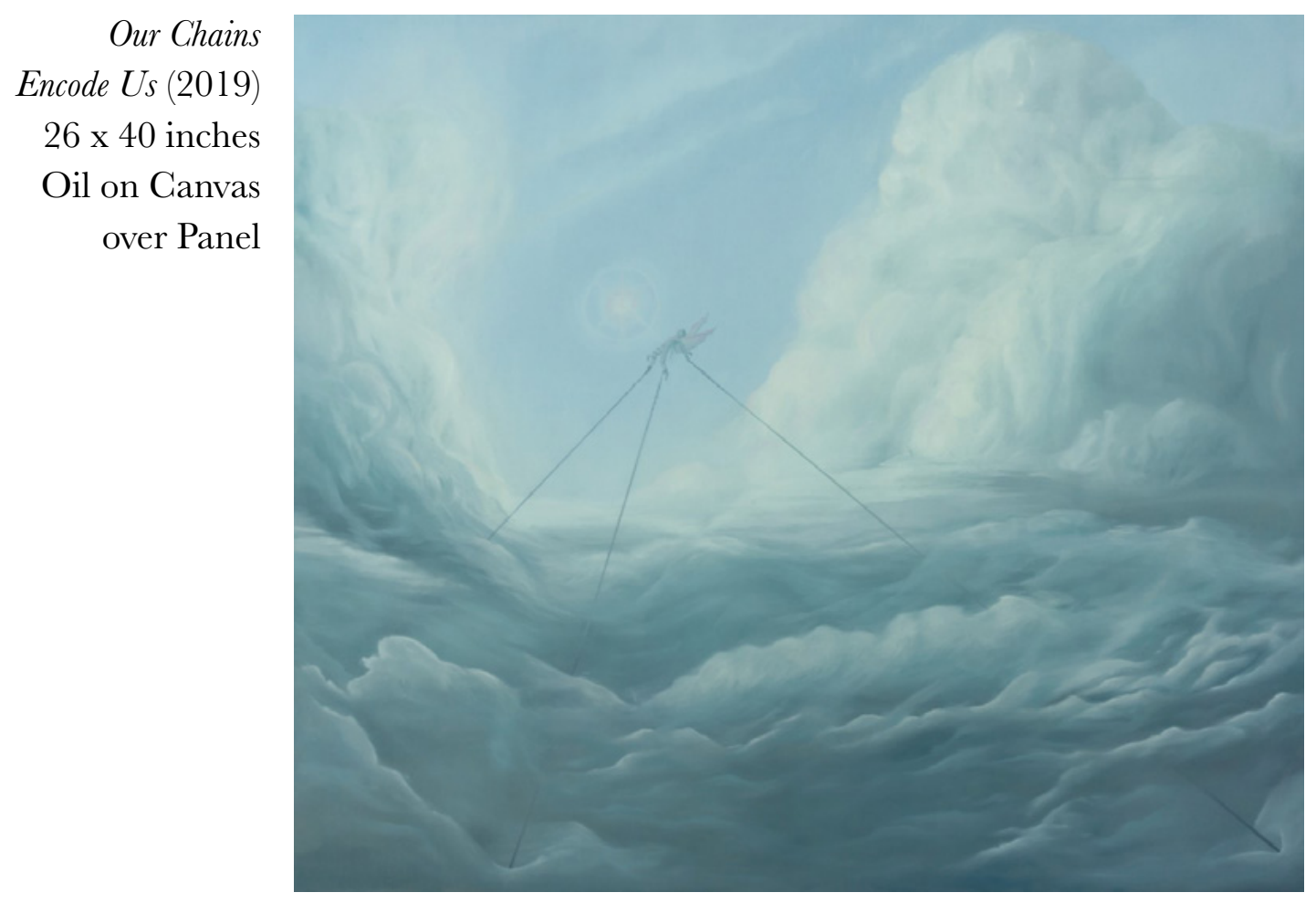

${ }^{4}$ Norman, Abby. "Ending Aging: Scientists Say Telomeres may be the Key to Unlocking Near- Immortality." Neoscope. Last modified May 12, 2017. https://futurism.com/neoscope/ending-aging-scientists-say- telomeres-may-be-the-key-to-unlocking-near-immortality. 
and herbal medicine, which a centaur Cheiron further hones. Certainly, Asclepius's most notable descendant is Hippocrates, the namesake of the Hippocratic Oath which every medical physician takes. After Asclepius reportedly raises the dead back to life, Zeus strikes him down, for he perceives the healer's medical prowess as a threat to the veil between humans and immortality. ${ }^{5}$ The figure in the painting represents a deconstructed Caduceus, adorned with wings and snakes, which hiss at the chains binding limbs to the ground below the cloudscape.

On a larger scale, at thirty-six by forty-two inches, the airy composition and subtle color palette draw the viewer's attention to the dynamic cloudscape before landing on the prisoner. A bright aurora symbolizes the allure of immortality. I arranged the chains toward the sun, indicative of the edges of a pyramid, a structure many ancient civilizations climbed in order to approach the heavens. Upon further inspection, the chains resemble the double-helical structure of DNA. As discussed previously, scientists work hard to succeed the natural limits of the organic form; however, our genetic features, such as the shortening of telomeres, impede the ascension. Just as Icarus flew too close to the sun after escaping prison, so does medicine haphazardly attempt to achieve immortality without fully understanding the consequences. Though contemporary science may never guarantee immortality, perhaps contemplating the preservation of our bodies may offer some consolation to the anxiety arising from leaving our mortal forms.

Despite attempts to live forever, it is perceivable that every living organism will someday die and leave behind remnants of their forms. With rare exception, such as bog-sunken or frozen mummies, bodies naturally decompose with the assistance of bacteria, fungi, and scavengers. With care however, our skeletons may survive centuries and be of use to future generations. Medical osteologists and anthropologists study bones to scientifically approach our futures and our pasts, respectively. At Texas Christian University (TCU), anatomists store skeletons in plastic tubs, as illustrated in the left panel of How Will You Be Preserved? (2019). The TCU Biology department teaches with these very skulls, which I photographed as reference for this piece. I compositionally separate two approaches to the preservation of the human skeleton across a diptych, with each panel measuring thirty-two by forty-two inches. I painted the background first in a few techniques, experimenting with wet-on-wet and wet-onto-dry as I covered the space. I designed the background pattern with photographs of lotus flowers, which represent rebirth. By using lotus flowers, I illustrated "life" beyond a grave, albeit without certainty of spiritual existence. The backgrounds and plane of the tables are synonymous between the two panels to imply the congruencies between the two camps of preservation. Many people believe science and religion oppose one another, but I reject this, seeing both function to relieve thanatophobia. Future biologists and healthcare professionals may study our remains to further their education. As previously mentioned, medicine works to extend the human lifespan and enhance the quality of life. By donating our bodies to science, we help future generations live longer, healthier lives. While some may seek the bodily privacy of a burial, there might be some consolation in knowing that choosing to donate your body will contribute to a greater cause.

${ }^{5}$ Cartwright, Mark. “Asclepius.” Ancient History Encyclopedia. Last modified June 20, 2013. https://www.ancient.eu/Asclepius/. 

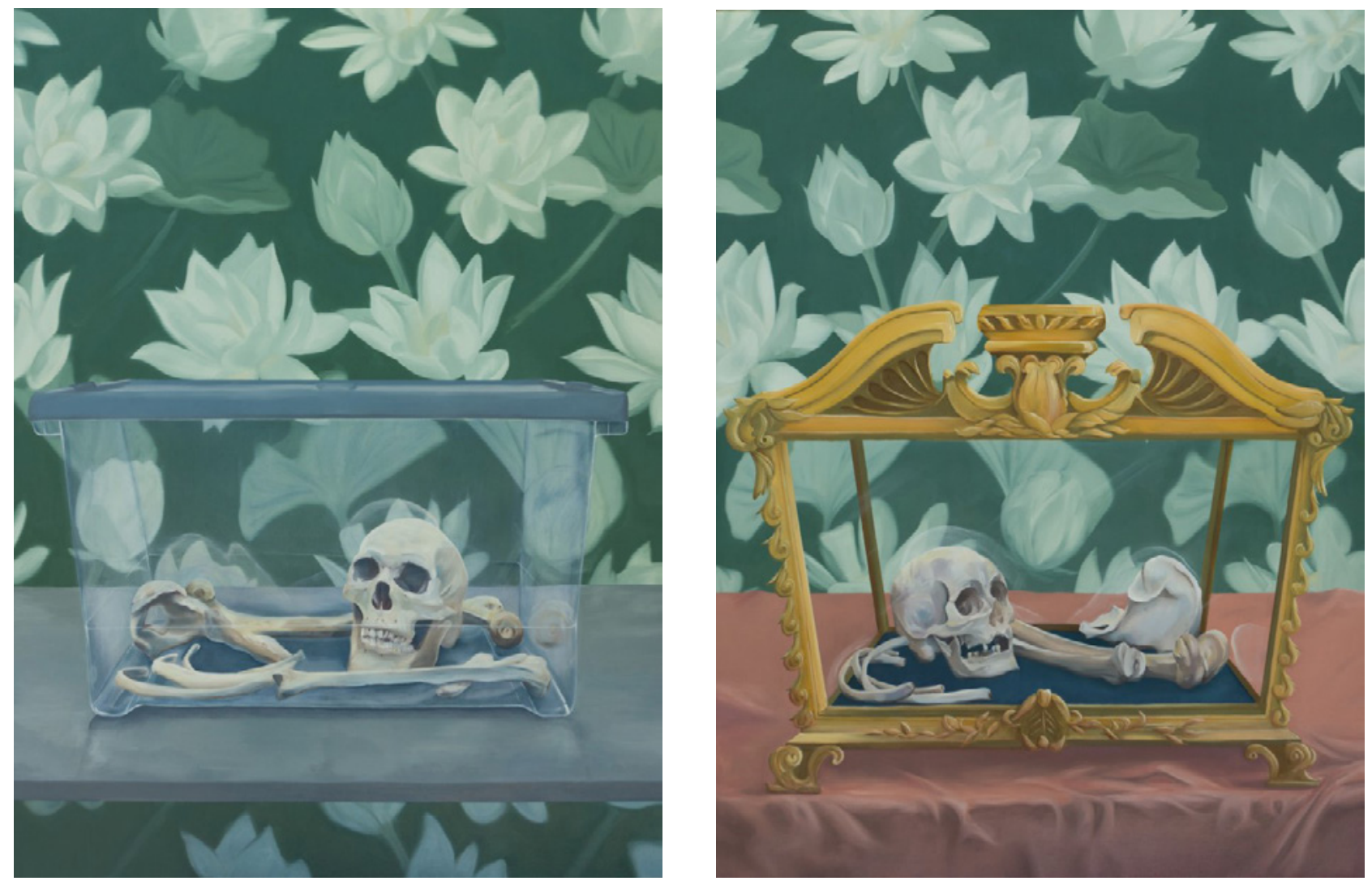

How Will You Be Preserved? (2019) Diptych; Each panel 32 x 42 inches Oil on Canvas over Panel

Historically, artists have used skulls to communicate mortality. Along with other Dutch masterpieces, Still Life with a Skull and a Writing Quill (1628) by painter Pieter Claesz uses realistic detail and an illusion of close proximity to force viewers to consider the transience of life. ${ }^{6}$ Even earlier, in the medieval period, monks would often place human skulls in their cells to help them remember their own mortality, meditate, and live intentionally. ${ }^{7}$ The experiential and emotional dimension of religion describes the feelings aroused by participation in spiritual traditions. ${ }^{8}$ These feelings may include relief or comfort in the promise of life after death. Religions vary greatly in ritual, but different beliefs of an afterlife all similarly depend on some realization that our biological life is temporary. While some medical scientists study skeletons to prolong our lifespans, religious institutions celebrate bones as a means to remind their followers that spirituality supersedes mortality. Anne Schuchman writes of Umiliana De Cerchi, a widow who dedicated her life to the Roman Catholic church in the thirteenth century. ${ }^{9}$

${ }^{6}$ Claesz, Pieter, Still Life with a Skull and a Writing Quill, oil on wood, 1628, The Metropolitan Museum of Art, New York City, NY. https:// www.metmuseum.org/art/collection/search/435904.

${ }^{7}$ Yalom, Staring, 32.

${ }^{8}$ Smart, Ninian. The World's Religions: Old Traditions and Modern Transformations. N.p.: Cambridge University Press, 1992.

${ }^{9}$ Schuchman, Anne M. 2001. "LITERARY COLLABORATION IN THE LIFE OF UMILIANA DEI

CERCHI." Magistra 7 (2) (Winter): 5. http://library.tcu.edu/PURL/EZproxy_link.asp?/login?url=https://search. proquest.com/ docview/216906891 ?accountid=7090. 
Umiliana's religious life gathered significant attention, such that just a few months after her burial in 1246, the Franciscan Basilica of Old Santa Croce exhumed her body and later preserved her bones in a gilded vitrine. Blessed as a saint in 1694, her bones remain on display to honor her and inspire spiritual devotion in church members and visitors.

While we may not all visit the Franciscan Basilica of Old Santa Croce, any first encounter with actual human remains, whether at a memorial service or in an anatomy lab, can serve as a powerful catalyst to awaken us to our own mortalities. Hardly though does everyday life provide opportunities that challenge our perception of existence beyond the present. The rightpanel of How Will You Be Preserved? (2019), illustrates the preservation of skeletons as inspired by Umiliana de Cerchi, resting on display for believers and tourists alike. I found inspiration for this piece after seeing Professor Adam Fung's images taken during a 2019 research trip to the Basilica of Old Santa Croce. In my painting I hope to convey the differences in luxury afforded to the preservations of bones by the church as opposed to the plastic containers used by scientists. Gold-clad leaves on the vitrine and silky linens flowing off the space express a certain romanticism, although this is certainly within reason given the skeleton's function here to honor spirituality. In the twenty-first-century, we should not expect that priests arrange our bones in gilded vitrines, but there is a strong demand for each of us to donate our bodies to scientific research, if we are so comfortable.

Preparing for the future by means of cremation, burial, donation, or otherwise forces us to consider tangible components of our deaths, by caring for our remains. Here we may exercise a form of control over the fate and legacy of our remains. Imagining our bodies absent of our soul or mind can bring us closer to acknowledging the imminent. Despite my bias toward the sciences, I do not propose either burial or donation as superior to one another. Though utilitarian, forcing all people to donate their bodies to science without regard to their comfort in the practice would intensify death anxiety. Instead, people should feel invited by conversation and art, such as in my honors thesis, to contemplate the finiteness of their own lives. By considering the fate of our own deceased forms, death is no longer an impersonal concept. While it may be tempting to believe death could never happen to yourself, intentional thought forces acceptance of mortality without abstraction. Death becomes an event rather than an idea.

The aftermath of death is both physical and metaphysical. Without life, our bodies physically break down as the atoms scramble to fulfill the universe's demands for a more entropic arrangement. Aspects of death are also metaphysical: the extinguishment of the mind, the release of the soul, the achievement of Moksha, the rebirth. To both dimensions, I attribute the future of the world after our deaths. The aftermath of death is physical in the sense that after we die, the earth continues to revolve around the sun. The unyielding seasons reveal the indifference of the world to our conscious existence. As Emily Dickinson writes,

"If I should die, And you should live, And time should gurgle on, And noon should burn, As it has usual done;" 10 
To imagine the world goes on without pause implies insignificance. Perhaps this aspect of death and dying explains the contemporary spread of the "fear of missing out." With increasing access to social media, one may quickly feel subdued by how frequently we seem to miss out on fun moments that we can see through our screens. It simulates how some may envision the afterlife - free to watch but never partake in the activity; that the world continues in our absence seems callous. However, the pressure of a world that cannot function without us might discourage thoughts of death altogether:

"[... 'Tis sweet to know that stocks will stand

When we with daisies lie,

$[\ldots]$ It makes the parting tranquil And keeps the soul serene[.]"10

The continuum of the universe can calm one's spirit and bring peace of mind. For some, the solution to death anxiety may be accepting that the world will not die alongside them, that the world retains their cherished places and their loved ones. How peaceful might we live and die if the weight of an entire world is lifted from our shoulders? After the end, at least in this form, we do not experience the world. Thus, I attribute any thoughts concerning the aftermath of our deaths to the metaphysical and therefore the hypothetical.

In visiting a nineteenth century cemetery in my Northeast Texas hometown, once in late March and later in mid-January, I saw the cyclical nature of the world. Tall grass and wildflowers shroud headstones in the growing spring, but cold winter frosts annually reveal those markers. Here I felt the persistence of the universe in our absence, followed by the serenity of knowing that even after my own death, these very stones will likely still stand, albeit more cracked. The vegetation will wax and wane as the Earth orbits the sun. To illustrate this experience, I took several digital photographs of the space and completed two smaller painting studies in reference to them. In Tombstone Among the Grass (2020), a toppled grave marker is super-imposed onto a painted grass fabric pattern, which I received from my grandmother as a child. In Tombstone Among the Leaves (2020), a notably damaged headstone stands reerected after falling to the ground. Time wields a heavy hand on the integrity of outdoor grave markers, and yet springing up between the fallen leaves grow delicate seedlings. In turn, these plants will grow higher than the marker itself, flatten when the wind topples the stones back to the ground again, and decay before another stranger stacks the pieces again. The cemetery lot serves as proxy to the entire universe - existing in revolving loops, peacefully indifferent to the temporary lives of us humans. Amongst tombstones I could never forget the imminence of death, yet at the same time, the persistence of life throughout the field makes it hard to fear mortality.

\footnotetext{
${ }^{10}$ Dickinson, Emily. "If I Should Die.”. https://poets.org/poem/if-i-should-die-54.
} 


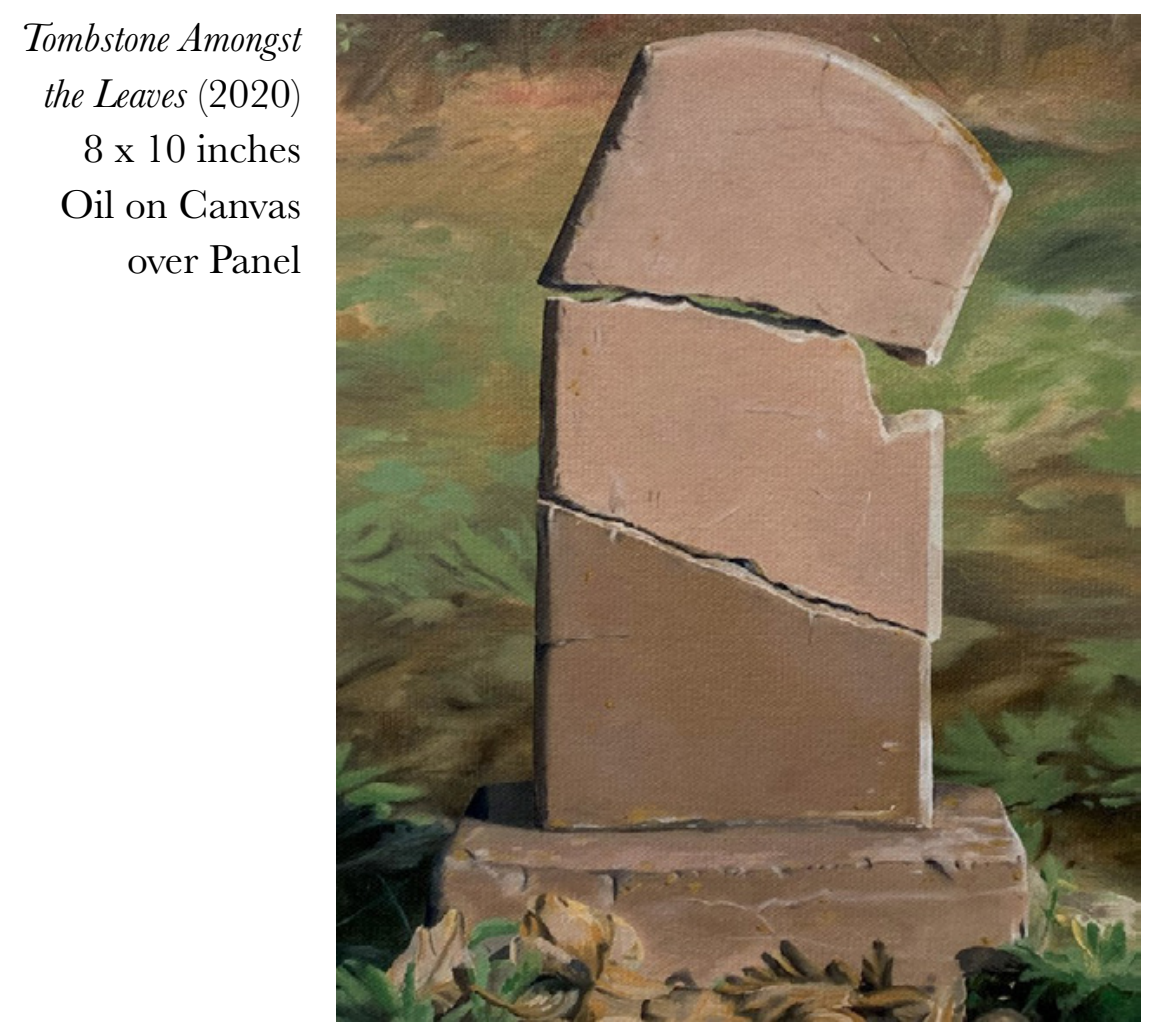

I tightened the composition of these paintings within the plane of the canvases. This comes from studying the work of Vija Celmins, whose retrospective exhibition of paintings I had the honor of seeing during an Honors Research trip to New York City. The concentration and proximity of art galleries in Manhattan offers a unique environment to study art history and contemporary artists. I explored museums across Manhattan to study different approaches of representing death in art. The American Museum of Natural History presents an anthropological time lapse of the diversity of the human experience. I used digital photography to document artifacts and placards from the exhibits for further study and incorporation into this project. Exhibits discussing religion, science, social cycles of life, and death rituals received extra attention. Stepping into the historical art scene, I began in the Whitney Museum of American Art. My lens of death anxiety in the United States of America heavily depends on the Abrahamic religious context of Western society; visiting the Whitney was critical to discover examples - or the lack thereof - of death in domestic art. Visiting the Museum of Modern Art presented an different approach to death in art in Francis Bacon's work from World War II, which depicts a rather gruesome, butcherous scene. ${ }^{11}$ This piece steered me away from using violence or gore in contemplative works focused on reducing death, since biologically, we respond with fearful disgust. In order to promote wholesome meditation on death, images imagery should be peaceful or, at the very least, not hellish.

\footnotetext{
${ }^{11}$ Bacon, Francis, Painting, oil and pastel on linen, 1946, The Museum of Modern Art, New York City, NY. https://www. moma.org/collection/works/79204
} 
At the Metropolitan Museum of Art (MMA), I studied historical artistic contexts. I looked through Greek, Roman, and Neoclassical sculpture to better understand approaches to rendering figures. Additionally, I observed European paintings to study different historical techniques and compositions and understand which elements artists use to imply death in artwork. The MMA dedicated an exhibit to Dutch masterpieces, which was insightful due to how many Dutch artists paint with such great precision while subtly referencing death and life. Finally, I visited the Egyptian, Middle Eastern, and Asian exhibits at the MMA to better appreciate how different cultures represent topics like death, especially considering they do not often share the same Abrahamic traditions as Western society. Before leaving the city, I visited eight independent galleries in the Chelsea district to study how contemporary artists arrange work in galleries and address present issues. This benefitted my own ability to work not just as an illustrator but as an artist working within the contemporary context as well. New York museums and galleries provided many opportunities to study skills and subject matters. I also learned to pay stronger attention to the surfaces of paintings after my trip. More importantly though, my experience affirmed how fully we can live when we accept that life is temporary and embrace new challenges. Ignoring our mortality does not slow the progression of time, nor does living our lives to the fullest accelerate it. When we let the inevitability of death motivate us to experience more, thanatophobia does not encumber us but, rather, enhances us.

I have suggested the importance of meditating on mortality. However, the busyness of life often competes for time that should be set aside for contemplation. Over reflecting on our own deaths, we prioritize more immediate demands: careers, family, entertainment - to name a few. We easily forget how important contemplation is, and unlike medieval monks, we might be alarmed by using a human skull to remind us of our mortality. However, the twenty-first-century commonplace of wearable technology, such as Apple Watches, provides a new platform to remind us of the imminence of dying. Co-founders Ian Thomas and Hansa Bergwall partnered to develop the app WeCroak, which randomly reminds wearers that they will die. ${ }^{12}$ Randomly, throughout the day, the app notifies users with the subject "Don't forget, you're going to die." The app delivers quotes from various authors, speakers, and poets to suggest topics on which to meditate. ${ }^{13}$ Ultimately our deaths may arrive just as unexpectedly as the unscheduled notifications. Death anxiety typically prevents the afflicted from experiencing new things and living their fullest lives. By actively meditating on death, it is possible to develop coping mechanisms and normalize the imminence of death. I designed this honors thesis to encourage viewers to contemplate their mortality, to feel unencumbered by death anxiety, and to be motivated to live ambitiously.

In my piece fust Beating isn't Enough (2020), I used reference photos of me taking my own pulse. The composition is set to first-person perspective, forcing the viewer into a personal position. At sixteen by twenty inches, my hands are slightly larger than life, but when viewed from a few feet away, my body aligns to overlap the figure in the painting. Not everyone can feel their heart palpitating when at rest;

\footnotetext{
${ }^{12}$ Bosker, Bianca. "The App That Reminds You You're Going to Die." The Atlantic, January 2018. https://www. theatlantic.com/magazine/archive/2018/01/when-death-pings/546587/.
}

13 "WeGroak." KKIT Creations. Update April 16, 2020. https://www.wecroak.com/\# 
but perhaps viewers of this painting will feel urged to check their own pulses as a reminder that their heart still beats. Drawing on the role of technology in our daily lives and its potential in meditation, I included my Apple Watch, which does receive notifications from WeCroak.

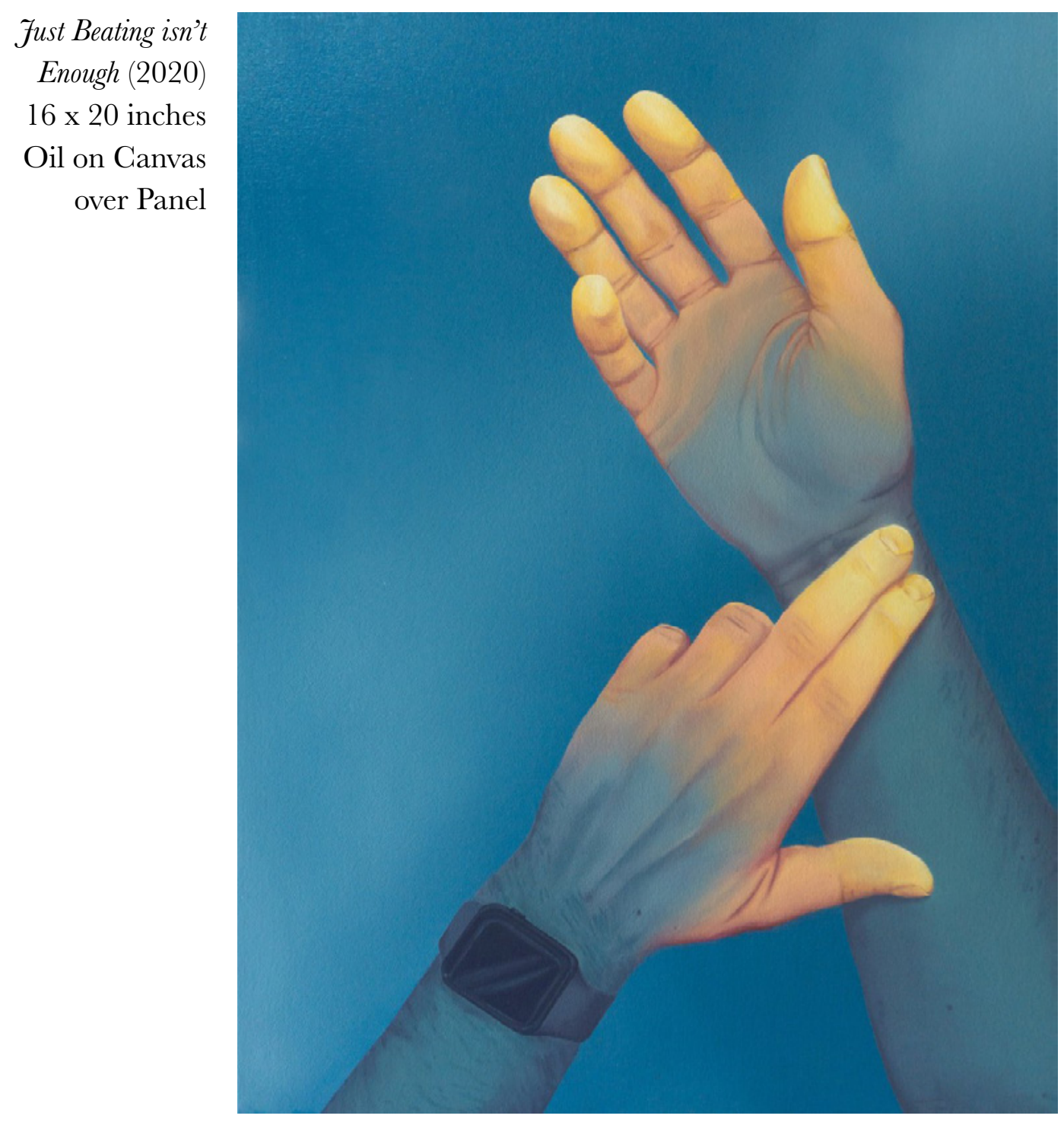

My goals for this piece include reminding people of the limits of longevity and how that should motivate us to experience new things and form deeper relationships with others. While our hearts may continue to beat, if we do not actively seek to experience what is real in life, are we truly living? These are questions posed by HBO's popular television science fiction, Westworld, in which animatronic robots achieve sentience through a series of life-altering struggles. ${ }^{14}$ The show forces us to consider the routine nature of our lives. The characters, human and robotic, live in repeated daily loops; which begs the

\footnotetext{
${ }^{14}$ Westworld. "The Passenger." Episode 10. Directed by Frederick E.O. Toye. Written by Jonathon Nolan,
} Lisa Joy, Gina Atwater, and Michael Crichton. HBO. June 2018. 
question, do our lives look like this? Waking up to an alarm, commuting to work, and watching the same television shows until we sleep, just to do the same tomorrow, might indicate that we have little in contrast with the artificial intelligence we seek to distance ourselves from. Nevertheless, unlike our current computers, we have the potential to seek unprogrammed experiences and have enriching lives. Knowing that this life is not eternal may pose a powerful motivator to break the loop and experience something new and real.

In fust Beating isn't Enough, I explored a new bolder color palette. Drawing on complementary pairings of oranges and blues, as well as purples and yellows, I created a dramatic scene that draws attention. Studying the work of contemporary artist Jenny Morgan, I cropped figures to just below the elbows and established a more vibrant palette. The edges of the substrate can compositionally limit how much of the figure is visible, a technique which saves time. Cropping can diversify a portfolio, while retaining a common motif of the body. Morgan is also quite color-competent, demonstrating masterful detail using subtle variation in tone and value. Like myself, she produces work concerning mortality, which has been very useful in further developing my iconography for death. In Jenny Morgan's oil painting, EXIT (2013), a figure holds an upside-down, jawless skull adorned with a thin golden halo, subtly marked out with an $\mathrm{X}$ in each of the orbital sockets, and a black flame burning above the teeth. ${ }^{15}$ To me, this painting represents a nurturing intimacy between life and death and offers the artist's acceptance of her own mortality. The approach to surface, composition, and color palette have impacted my own artistic decisions for Just Beating isn't Enough and There is Fellowship in Death (2020).

Further exploring time and painting surface, I began a small eight-inch tondo (round) canvas, Extinguished (2020). As in Tombstone Among the Grass (2020), I sanded this background to reveal the canvas weave underneath. Coincidentally resembling denim, I believe this piece is indicative of Americana and hints at the nature of U.S. society to shy away from the topic of mortality. Over the course of this project, each time I struck a match, I saved it in an empty matchbox. Arranged in twelve intervals around the tondo, the length of burning along the matchstick increases clockwise, illustrating the flames that lived longer amounts of time. Biological life is temporary. Many of us do not anticipate that we will die soon, but it is the very nature of death to be unexpected. When will that existing flame burn out - at 11:59 or 6:01?

While I use the matches as metaphor for human life, they fall short in some degree. Namely, the viewer must not believe that by blowing out matches earlier, I robbed them of the rest of their lives. A silly notion here, but one that on a realistic level pervades our thoughts of people dying young. While we hope for a long, healthy life for ourselves and others, the saddening fact is that people of all ages are susceptible to sometimes accidental or unpreventable death. Nevertheless, a life of any duration can be well-lived and full of engaging relationships. As readers, we do not value novels more than short stories. I believe the fragility of life ordains a sense of value to our time on Earth, which others should interpret as motivation to live ambitiously instead of shelter from the world. Any predictions we make about our longevity are complete guesses; therefore, we must be earnest to maximize our human experience.

\footnotetext{
${ }^{15}$ Morgan, Jenny, EXIT, Oil on Canvas, 2013, Private Collection, New York, In How To Find A Ghost, by Benjamin Genocchio, 31, Driscoll Babcock Galleries, 2013.
} 

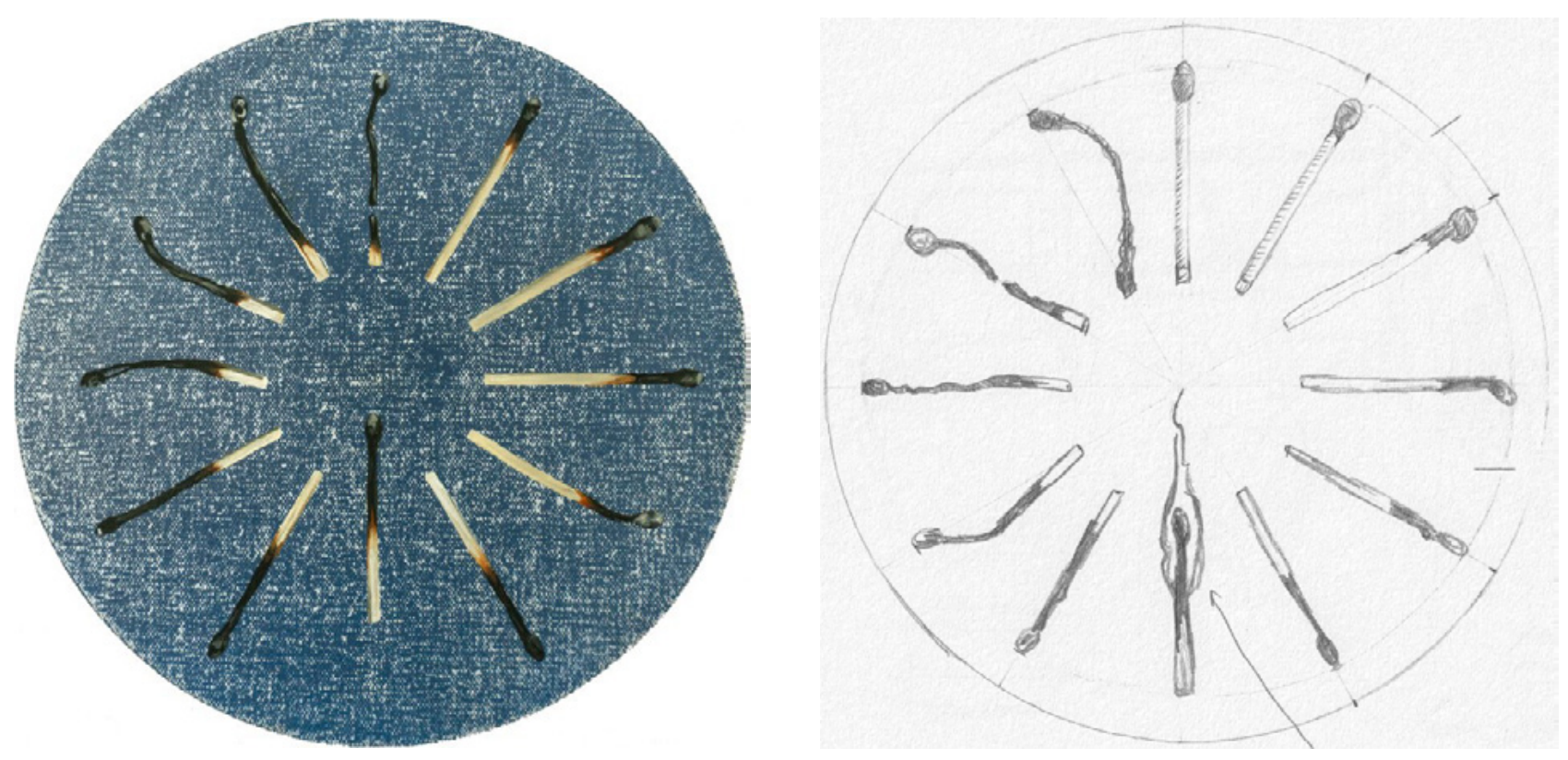

Extinguished (2020) 8-inch-diameter tondo

Oil on Canvas over Panel

Work-in-progress (left); Sketch (right)

Having already mentioned the powerful motivation that death anxiety has on living a fuller life, I shift the attention to how embracing the universal experience of death can lead to deeper interpersonal relationships. Irving Yalom writes of the difference between everyday and existential loneliness. To borrow from Susan Sontag's Illness as Metaphor, "Everyone who is born holds dual citizenship in the kingdom of the well and in the kingdom of the sick," which illustrates the mode of self-isolation of the healthy from the dying as written by Irving Yalom. ${ }^{16}$ Many societies have transferred the act of dying to "sequestered [...] curtained hospital bed $[\mathrm{s}]$ " and nursing facilities instead of homes, surrounded by family. ${ }^{17}$ The result is a psychological distancing of oneself from the inevitability of their own death.

Additionally, Yalom describes existential isolation, how individual experiences, memories, and emotions shape reality. In dying, you lose not only biological life but also "your own rich, miraculously detailed world, which does not exist in the same manner in the mind of anyone else." 18 This claim, that our cherished experiences vanish when we die, may appear to contradict my previous claim that we can find peace in knowing that the world persists after our deaths. It is important to note, however, that it is

\footnotetext{
${ }^{16}$ Sontag, Susan. Illness as Metaphor. New York City: Picador, 1978, 3.

${ }^{17}$ Yalom, Staring, 118.

${ }^{18}$ Yalom, Staring, 121.
} 
not the entire world which vanishes, but instead individual unique perception of the world. Yalom states that isolation exacerbates thanatophobia, for "dying [...] is lonely, the loneliest event of life."19 It is no wonder that the number of in-person and online support groups for terminally ill patients has skyrocketed in the past few decades. Forming empathetic relationships throughout our lives, in which communication about dying occurs intentionally, catalyzes deeper relationships and weakens the weight of loneliness on death anxiety.

My hope for this project is to communicate not only that we all, in some degree, are fearful of mortality, but especially that it is important to recognize our own death anxiety. Since death is a universal human experience, it is equally important to question why conversations about death so rare among healthy people. What influence do discussions about death with members of your inner circle on your ability to live freely and connect with others? In my painting There is Fellowship in Death (2020), I illustrate the positive energy associated with death-focused conversations. By reaching from the cooler edges of the composition, the figures warm as they approach the central skull, a literal interpretation of death. As fingers and palms contact the skull, they illuminate a brighter positive warmth. Indicative of heat-mapping, I wanted this painting to illustrate the life we feel in community, as opposed to the cold darkness of isolation.

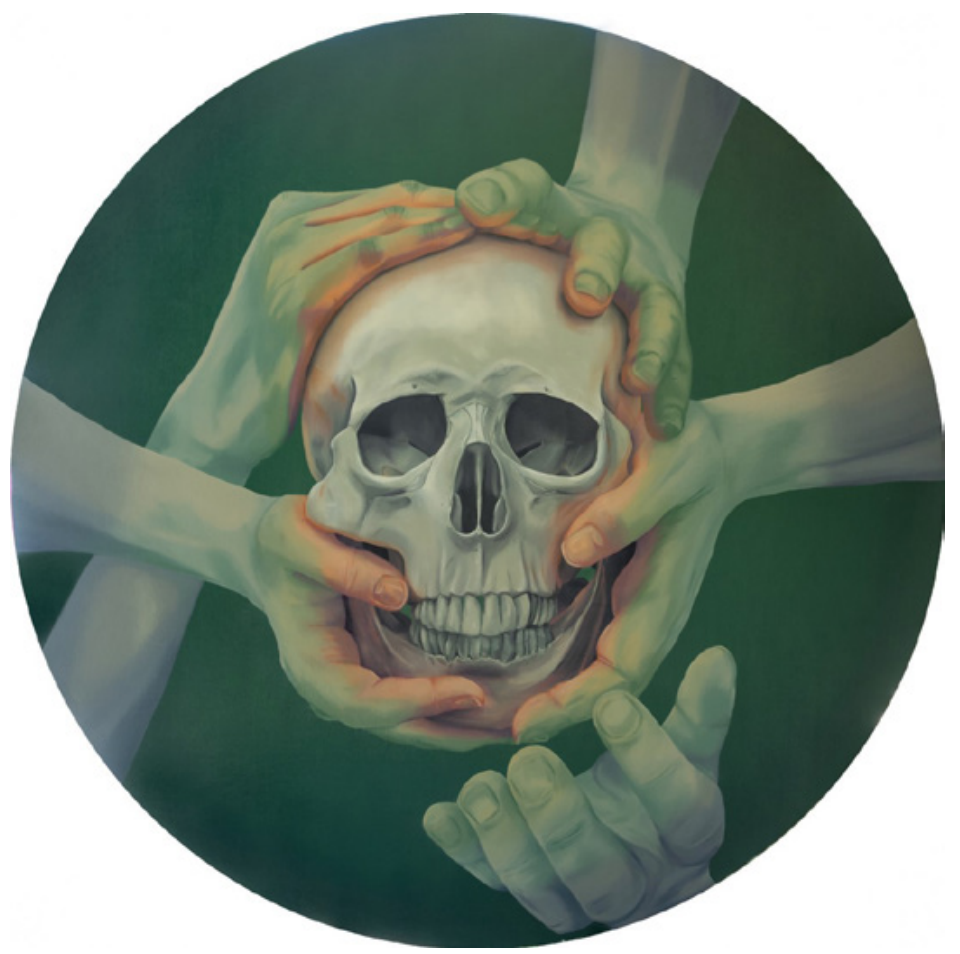

There is Fellowship in Dying (2020)

36.5-inch diameter tondo

Oil on Canvas over Panel

${ }^{19}$ Yalom, Staring, 119. 
I painted There is Fellowship in Death (2020) on a thirty-six-inch diameter tondo (round) canvas stretched over Masonite panel. I painted a cool-to-warm gradient from the circumference to the center and sketched the figures on the sanded background. I must thank my friends for serving as hand models for this piece in a previous shoot with a plastic skull. My friends and I have conversations about greater topics, like death and faith, which I strongly believe have deepened the bonds between us and alleviated my death anxiety. A goal for this piece is to inspire others to communicate death anxiety to others. As Yalom states most eloquently, "It is the synergy between ideas and intimate connection with other people that is most effective both in diminishing death anxiety and in harnessing the awakening experience to effect personal change." ${ }^{20}$ Isolation is a primary source of negative energy and often strongly inhibits the extents to which people live ambitious lives. By accepting our fears, sharing our unique cultures, and bonding over common human experiences, namely mortality, people of both secular and religious beliefs can achieve greater connectedness.

Having shown development in thought above, this paragraph seeks to form final relationships between elements of my paintings. It is important for a series of work to also demonstrate advancement of skill and connect to form a greater whole. I began with Remembrance which, rather didactically, uses a figure and floral motifs to express mortality and honor. I have frequently used horticultural and figurative motifs to bridge many paintings together. The relationship between mortality, science, and religion appears in several pieces. Stylistically, each painting depends upon on romanticized realism, from the mirror-like details of Self, to the waterfalling clouds of Our Chains Encode Us, and the dry simplicity of both tombstone paintings. This thesis has served as an experiment for me as an artist. Universal connections in palette and surface are sparse, since I changed direction midway through the project to embrace more vibrantly colored figures and sanded textures. Ultimately, I find the most unifying feature of the series to be the focus on subject matter typically unaddressed in Western society, namely aspects of death anxiety. Individually, the pieces are quite unique, but when placed together the details in subject matter, composition, palette, and technique form a web of connections across pieces.

The human sense of conscious self is a double-edged sword. Humans can recognize and appreciate the wonderful beauty of the natural world. We can celebrate relationships with others of our own species and form emotional bonds to animals. But this special awareness to reality comes at a costhumans are aware of their own mortality. For centuries, many societies have indoctrinated a fear of dying, which inhibits people's ability to seek fulfilling lives and deep relationships. By countering this precedent and intentionally contemplating death, we seek means to explore new secular and religious approaches to dying. I do not expect the reader to begin painting skulls or tombstones but, rather, to seek spiritual novelty and customized coping mechanisms. Individuals are responsible for generating their own spiritually and intellectually satisfying beliefs, and neither I nor any priest can provide a universal answer. True, we all fear death to some degree; we are a species designed to survive. While many seek relief in medicine, spirituality, or legacy, I argue that, as of 2020, none of this can guarantee immortality. We must acknowledge the finite nature of our biological lives as real, future events.

${ }^{20}$ Yalom, Staring, 119. 
Contemplating death may not completely eradicate death anxiety, but I hope that by focusing on the inevitable, the viewer or reader discovers a more manageable perception of mortality and use it as motivation to live ambitiously with deep relationships. Though finite, I would call this, a life well-lived. 


\section{Bibliography}

Bacon, Francis, Painting, oil and pastel on linen, 1946, The Museum of Modern Art, New York City, NY. https://www.moma.org/collection/works/79204

Bosker, Bianca. "The App That Reminds You You're Going to Die.” The Atlantic, January 2018. https://www.theatlantic.com/magazine/archive/2018/01/when-death-pings/546587/.

Cartwright, Mark. "Asclepius.” Ancient History Encyclopedia. Last modified June 20, 2013. https://www. ancient.eu/Asclepius/.

Claesz, Pieter, Still Life with a Skull and a Writing Quill, oil on wood, 1628, The Metropolitan Museum of Art, New York City, NY. https://www.metmuseum.org/art/collection/search/435904.

Dickinson, Emily. "If I Should Die.” https://poets.org/poem/if-i-should-die-54

Morgan, Jenny, EXIT, Oil on Canvas, 2013, Private Collection, New York, In How To Find A Ghost, by Benjamin Genocchio, 31, Driscoll Babcock Galleries, 2013.

Norman, Abby. "Ending Aging: Scientists Say Telomeres may be the Key to Unlocking Near-Immortality.” Neoscope. Last modified May 12, 2017. https://futurism.com/neoscope/ending-aging-scientists-say-telomeres-may-be-the-key-to-unlocking-near-immortality. "The Rod of Asclepius and Caduceus: Two Ancient Symbols.” Florence Inferno. Last modified June 22, 2016. https://www. florenceinferno.com/rod-of-asclepius-and-caduceus-symbols/.

Schuchman, Anne M. 2001. "Literary Collaboration in the Life of Umiliana Dei Cerchi." Magistra 7 (2) (Winter): 5. http://library.tcu.edu/PURL/EZproxy link.asp?/login?url=https:// search.proquest.com/ docview/216906891 ?accountid=7090.

Smart, Ninian. The World's Religions: Old Traditions and Modern Transformations. New York: Cambridge University Press, 1992. 
Sontag, Susan. Illness as Metaphor. New York City: Picador, 1978, 3.

"WeCroak." KKIT Creations. Update April 16, 2020. https://www.wecroak.com/\#

Westworld. “The Passenger.” Episode 10. Directed by Frederick E.O. Toye. Written by Jonathon Nolan, Lisa Joy, Gina Atwater, and Michael Crichton. HBO. June 2018.

Yalom, Irving D. Staring at the Sun: Overcoming the Terror of Death. San Francisco: Jossey-Bass, 2008, 32-121. 